SHS Web of Conferences 24, 01014 (2016)

DOI: $10.1051 /$ shsconf/20162401014

(C) Owned by the authors, published by EDP Sciences, 2016

\title{
Research of low-carbon transition path of star hotels--A case study of Guilin
}

\author{
Fengling Tang \\ School of Economics and Management, Wuzhou University, Wuzhou, Guangxi, China
}

\begin{abstract}
A general trend of the world economic development is the low-carbon economic transition. With a wide influencing range and rapid development, the hotel industry has prominent problems in the energy consumption, resources occupancy and environmental unfriendliness, so it is imperative to develop low-carbon hotels. This paper proposes the low-carbon transition of the star hotels in Guilin in terms of constructing the energy conservation and innovative management mode, adopting new technologies and ways, developing low-carbon hotel products and guiding low-carbon consumption through analysis about the inevitability of establishing low-carbon hotels in Guilin, the running status of the existing star hotels and the situation of energy consumption thus further promoting the development of low-carbon tourism in Guilin.
\end{abstract}

Keywords: low-carbon economy; low-carbon hotel; Guilin; star hotel

\section{INTRODUCTION}

With the rapid growth of the global economy, energy consumption and carbon dioxide release generate a huge impact on the environment of human life. In 2009, the Copenhagen Climate Conference raised the issue of global climate change again, and the conference indicated that the low-carbon economy would be a choice to deal with climate warming. The State Council's Suggestions on Accelerating the Development of Tourism clearly puts forward that, in order to advocate the low-carbon travel mode, implement the water-saving, energy-conservation and emission-reduction projects, promote the energy conversation and environmental protection and implement the energy performance contracting, the amount of water and electricity consumption in star hotels and scenic spots will be reduced by $20 \%$ in five years. The research shows that, in one year, a medium-scale three-star hotel consumes about 1,400 tons of coal and releases at least 70 tons of soot, 28 tons of sulfur dioxide and 4,200 tons of carbon dioxide into the air; in one year, a large-scale hotel with the building area of approximately 90,000 square meters consumes about 130,000 to 180,000 tons of standard coal ${ }^{[1]}$. Thus, the hotel industry has a very high dependence on the energy and bears responsibility for emission of $5 \%$ of the global greenhouse gas. As an international tourism metropolis, Guilin walks in the front rank of the low-carbon action and introduces the low-carbon economy in the hotel industry. The low-carbon transition of the star hotels is in line with the requirements of the comprehensive pilot regions of the national tourism.

\section{FORMING BACKGROUND AND CHARACTERISTICS OF LOW-CARBON HOTELS}

"Low-carbon economy" was first appeared in a white paper-Our Future Energy: Creating Low-carbon Economy published in the UK on February 24, 2003. "Low-carbon economy" can obtain the most economic output through the least consumption of natural resources and pollution, which is a path and opportunity to create a higher living standard and a better quality of life. What's more, it creates opportunity for the development, application and output of the advanced technology, and also creates more new business opportunities and job opportunities. With the proposal and development of "low-carbon economy", the low-carbon tourism is also produced. The low-carbon tourism is required to obtain the environmental, economic and social benefits with the minimal energy consumption and carbon emissions in the production 
process of tourism. In the prevailing era of low-carbon economy, problems in consumption of a large number of energy, wasting of resources and environmental pollution all exist in the hotel industry, as one of three pillars of the tourism industry. Therefore, it is unable to further promote the development model of high energy consumption and high pollution, but there is a need to transform the mode of production. The low-carbon transition and creation of low-carbon hotels will be the direction of future development in the hotel industry.

Based on the concept of the sustainable development of energy conversation and consumption reduction, the low-carbon hotels adhere to the cleaner production, save energy and resources, reduce carbon emissions, advocate low-carbon consumption and reduce the operating costs of the hotels, thus achieving the economic, social and environmental benefits of hotels. As a new development pattern of resources conservation and focusing on sustainable development, the low-carbon hotels are characterized by the low emission, the low energy consumption, the low pollution and high efficiency and the high performance and benefits, which focus on the environmental protection. The low-carbon hotel is the specific application of the low-carbon economy in the hotel industry, which is an inevitable choice for the hotel industry to achieve sustainable development in the future.

\section{INEVITABILITY OF LOW-CARBON TRANSITION OF STAR HOTELS IN GUILIN}

(1) Need of establishing pilot regions for comprehensive reforms of national tourism in Guilin

In 2009, the State Council released the State Council's Several Suggestions on Further Promoting Economic and Social Development in Guangxi, which clearly put forward "the establishment of pilot regions for comprehensive reforms of national tourism in Guilin". Guilin has become China's first city to establish the pilot regions for comprehensive reforms of tourism, which eliminates marginalized crisis in Guilin and provides opportunities to transform the mode of economic development. Guilin should not only conduct reform in terms of the tourism, but also should be bold to reform and innovate in various industries and fields, thus providing a reference model for the national tourism and even the economic development. The low-carbon transition of the hotel industry in Guilin can promote the transformation of the economic development mode of the tourism in Guilin, which is a need of establishing the comprehensive pilot regions of national tourism.

(2) The Need of conforming to the green consumption and enhancing the core competitiveness of the hotel

With the continuous improvement of people's living standard, people pay more attention to the health and comfortable green consumption compared with adequate or ample food and clothing. With the growing environmental awareness of the consumers, the development trend of green consumption is irreversible although the process to popularize green consumption needs time in China, and there are some obstacles on the path of development. In the fierce market competition, the star hotels in Guilin can seize the chance of this new market demand, adopt the new technology, introduce the low-carbon guest rooms and dining and provide the low-carbon services and other low-carbon hotel products, which can not only save operating costs, but also reduce pollution, improve the quality of the surrounding environment and display their own low-carbon corporate image to the public so that the hotels can win the trust of the guests in the fierce market competition, enhance the hotel's reputation and public image, make the hotel's guests sufficient, improve the corporate's intangible assets and brand benefits, and ultimately enhance the core competitiveness of the hotel enterprise.

(3) Need of achieving sustainable development for hotels

In recent years, with the growing global demand for energy and shortages of resources, the price of the coal, electricity, oil, water and other energy continues to rise, and the cost of energy consumption in the hotel industry also continues to rise. Taking China's four-star hotel as an example, the average energy consumption per square meter is $100-200 \mathrm{~kW} / \mathrm{h}$, which is 20 times of that of the ordinary residential buildings; the per capita water consumption is $5-8$ times of that of the ordinary people; the cost of energy consumption approximately accounts for $13.3 \%$ of the operation revenue, which is twice more than the current cost of energy consumption in the international hotel $^{[2]}$. In recent years, the farmhouse inns and family inns have sprung up in Guilin. The tourists may select inns and hotels that are close to the scenic spot and relatively cheap in the selection of accommodation, and the star hotels face with the market challenges of the inns and hotels. The low-carbon transition of the star hotels in Guilin is an effective way to achieve the goals of cost reduction and benefit increase, enhance the market competitiveness and promote the sustainable development of the hotels.

\section{ANALYSIS OF ENERGY CONSUMPTION AND CARBON EMISSION OF STAR HOTELS IN GUILIN}

(1) Overview of star hotels in Guilin

In 1973, Guilin was listed as one of the first batch of 24 tourist cities that are opening to the outside world and one of tourist cities that built up restaurants concerning foreign affairs. What's more, it established the large-scale wholesale market of the tourist commodities and formed a relatively complete system of tour- 
SSHE 2015

Table 1. Quantity of star hotels in Guilin from 2008 to 2012 (unit: hotel)

\begin{tabular}{|c|c|c|c|c|c|}
\hline Year & Five-star & Four-star & Three-star & Two-star & Total \\
\hline 2008 & 4 & 13 & 38 & 16 & 71 \\
\hline 2009 & 4 & 12 & 42 & 15 & 73 \\
\hline 2010 & 4 & 12 & 39 & 13 & 68 \\
\hline 2011 & 5 & 11 & 40 & 13 & 69 \\
\hline 2012 & 5 & 12 & 40 & 12 & 69 \\
\hline
\end{tabular}

Table 2. Number of bed rented of star hotels in Guilin from 2008 to 2012

\begin{tabular}{|l|l|l|l|}
\hline Year & Number of bed & Average rental rate (\%) & Number of bed rented (million beds /night) ${ }^{\alpha}$ \\
\hline 2008 & 23174 & 48.21 & 4.08 \\
\hline 2009 & 22490 & 53.37 & 4.38 \\
\hline 2010 & 23557 & 56.76 & 4.88 \\
\hline 2011 & 22848 & 55.49 & 4.63 \\
\hline 2012 & 22840 & 53.17 & 4.43 \\
\hline
\end{tabular}

Note: $\alpha=$ number of bed $\times 365 \times$ average rental rate of the guest room

ism industry and tourist accommodation facilities integrated with "dining, housing, traveling, playing, shopping and entertaining" in the earlier days. Guilin is renowned by a good reputation of "Guilin's scenery is the best in the world", and attracts tourists at home and abroad with a prosperous development of the tourism industry and ever growing hotel industry (see Table 1). Moreover, various types of economic hotels such as the City Comfort Hotel, Home Inn and Hanting Hotel also seize the chance.

(2) The situation of the energy consumption and carbon emission of star hotels in Guilin

The amount of energy consumption of star hotels in Guilin is estimated according to the statistics of the tourist hotel industry in Guangxi Statistical Yearbook and the National Tourism Statistical Bulletin from 2008 to 2012.

Due to different energy consumption of the accommodation units in different countries and regions, in estimation of the global tourism industry, Gossling takes the average unit energy consumption as $130 \mathrm{MJ} /$ bed - day ${ }^{[3]}$; Shi Peihua and $\mathrm{Wu} \mathrm{Pu}$ believe that Chinese hotel's awareness of the environmental protection is not strong in the research of the energy consumption in China's tourist hotel industry, the average "age" of the hotels is relatively large, and the actual energy consumption is higher than the global average, so they believe that the unit energy consumption is $155 \mathrm{MJ}$ bed per day regardless of the hotel rating ${ }^{[4]}$.

This paper adopts the "bottom-up" estimation model based on the number of tourists who have reached the tourist destinations to calculate the energy consumption and carbon emission upward step by step. The specific statistical method used is as follows:

$$
L E=\sum_{i=1}^{n} p \bullet l e i
$$

In the above formula: LE is the energy consumption or carbon dioxide emission in the tourism industry or each department of the tourism industry; $\mathrm{P}$ is the scale of specific aspects of tourist activities (dining, housing, traveling, playing, shopping and entertaining); lei is the unit energy consumption or carbon dioxide emission of a certain part in the tourism industry.

The energy consumption of star hotels in Guilin from 2008 to 2012 can be calculated according to the formula by substituting the parameters of the energy consumption value and the number of bed rented in Table 2 into the formula (see Table 3).

Table 3. Energy consumption of star hotels in Guilin from 2008 to 2012

\begin{tabular}{|l|l|}
\hline Year & Energy consumption $(\mathrm{Pj})$ \\
\hline 2008 & 0.63 \\
\hline 2009 & 0.68 \\
\hline 2010 & 0.76 \\
\hline 2011 & 0.72 \\
\hline 2012 & 0.69 \\
\hline
\end{tabular}

Table 4. Carbon dioxide emission of star hotels in Guilin from 2008 to 2012

\begin{tabular}{|l|l|}
\hline Year & Carbon dioxide emission(Mt) \\
\hline 2008 & 0.18 \\
\hline 2009 & 0.19 \\
\hline 2010 & 0.21 \\
\hline 2011 & 0.20 \\
\hline 2012 & 0.19 \\
\hline
\end{tabular}


According to the research data of Schafer \& Victor (1999) and Gossling (2002), and the research results of Shi Peihua (2011), the carbon emission per bed per night in the hotel takes $43.2 \mathrm{~g} \mathrm{CO}_{2} / \mathrm{MJ}$. The carbon emission of star hotels in Guilin can be calculated according to the formula by substituting the parameters of the carbon dioxide emission per bed per night and the parameters of the number of bed rented in Table 2 into the formula (see Table 4).

The occupancy rate of the hotel is relatively low in 2008 and 2009 due to the snowstorm and earthquake in 2008 , but has a rapid growth in 2010. And later, it presents a declining trend. As can be seen from Table 3 and Table 4, the development tendency of the energy consumption and carbon dioxide emission of star hotels in Guilin from 2008 to 2012 presents a curve type. In recent years, the value has decreased, which has been much higher than that of other countries or regions compared to the carbon emission of $800 \mathrm{Kg}$ in the hotel industry of Seychelles.

(3) Situation of energy consumption of star hotels in Guilin

According to statistics, the cost of energy consumption of star hotels in Guilin approximately accounts for $10 \%$ to $20 \%$ of the operating cost of the hotel, and the natural gas and electricity are the main sources of energy consumption. The annual consumption of natural gas is approximately $350,000 \mathrm{~m}^{3}$, the daily power consumption is approximately 24,000 degrees, and the annual consumption is approximately 8.76 million degrees, which is mainly for air-conditioning and lighting, respectively accounting for $75 \%$ and $15 \%$ of the total electrical energy consumption ${ }^{[5]}$; the usage rate of the energy saving lamp is approximately $70 \%$ to $80 \%$, and the dimmer intensity can be scientifically adjusted based on the number of guests; the daily water consumption is approximately 450 tons, and the annual consumption is approximately 164,300 tons. Currently, the water recycling system is not used, and the main water-saving measures are respectively the switch-control, the reduction of the closestool water volume, campaign or other forms. In addition, and the clean energy has not yet been used in the star hotels in Guilin.

In summary, the number of bed rented of star hotels in Guilin from 2008 to 2012 fluctuates with the decrease or increase of the average rental rate and presents a curved development tendency. The cost of energy consumption of the hotel is relatively high, and the water and electricity consumption is large; the clean energy is not used; the energy consumption and carbon dioxide emission reduces from 2010 to 2012, but with a slight extent. Those all indicate that the star hotels in Guilin still have deficiency in the energy conversation, reduction of the energy consumption, environmental protection or other aspects. Therefore, it is imperative for the star hotels in Guilin to follow the low-carbon path.

\section{WAYS OF LOW-CARBON TRANSITION OF STAR HOTELS IN GUILIN}

\subsection{Construction of energy conservation and innova- tive management mode}

1. Establish organizations and systems of energy conservation and emission reduction

The hotel can set up a special organization of energy conservation and emission reduction to be responsible for the energy conservation and emission reduction of the hotel, developing the target and implementation scheme of energy conservation and emission reduction, preparing for the implementation rules of energy conservation and emission reduction of the hotel and supervising the implementation of energy conservation and emission reduction. A senior leader can be responsible for the hotels of four-star and above in Guilin. A responsible person can be designated by each department to participate in and constitute a team of energy conservation and emission reduction; the hotels of three-star and below can set up the commissioners of energy conservation and emission reduction in the hotel to directly supervise the energy conservation and emission reduction of the hotel under the leadership of the general manager, and also set up one or two staffs subordinated to the commissioners of energy conservation and emission reduction. There is a need to establish the low-carbon management system for monitoring and statistics of the energy use condition of the hotel, in order to timely detect problems, solve the problem of energy waste in hotel and control over the consumption of energy and materials of the hotel by the new technology and improve the usage rate of the energy and materials, thus reducing the waste of energy and materials and promoting the low-carbon work of the hotel.

2. Wake whole staff's awareness toward the energy conservation and emission reduction

Staff is the master of the hotel, and the operation and development of the hotel is inseparable from the promotion and efforts of the staff, so the improvement of the staff's awareness of energy conservation and emission reduction is a basic guarantee for the hotel to carry out energy conservation work. Therefore, the whole staff must participate in the energy conservation and emission reduction of the hotel. In the process of promoting energy conservation and emission reduction, the premise of carrying out energy conservation and emission reduction in the hotel is the staff's understanding about the knowledge related to low carbon. There is a first need to do internal communication, training and publicity, organize the staff to learn the knowledge related to energy conservation and emission reduction, carry out knowledge contest and other activities related to the energy conservation and emission reduction or environmental protection, publicize and educate the staff through the newspapers and magazines and blackboard newspapers of the hotel. 


\subsection{Application for new technologies and ways}

\subsubsection{Application for new technologies}

(1) Water source heat pump technology

Water source heat pump technology is characterized with high efficiency, free pollution, multiple purposes and the use of renewable energy sources. Water source heat pump system has a requirement on the water source, that is, adequate and stable water volume, suitable water quality and moderate water temperature.

The surface water resources are evenly distributed by the reconstruction of the water system around two rivers and four lakes of Guilin. The star hotels around the area of the rich surface water sources have environmental advantages of using the water source heat pump system. For example, Guilin Hotel, Guihu Hotel, Lijiang Waterfall Hotel, Royal Garden Hotel, Sheraton Hotel lay a good foundation for the use of the water source heat pump system, and adopt the water source heat pump technology to achieve the effect of energy conservation and emission reduction. If all-star hotels in Guilin can use the water source heat pump technology, air environmental pollution can be effectively reduced every year.

(2) Building automatic control system

The building automatic control system achieves automatic control based on the environmental parameters of the space, that is, automatic control of the space humidity, temperature, anion, fresh air and sterilization, thus enhancing the operating efficiency of the equipment and reducing the running time of the equipment. For example, the infrared technology can automatically adjust the indoor temperature according to the movement of people in space and the temperature of body, timely make a dynamic regulation based on the occupancy status of the guest rooms and reduce the energy consumption under the premise of the comfort of guests. The use of the building automatic control system can not only ensure the comfort of the hotel, but also reduce invisible waste of energy of the hotel. It is proposed that the three-star and above hotels in Guilin can adopt the building automatic control system.

(3) Reuse system of reclaimed water

In recent years, the reclaimed water reuse technology has been widely used in Japan, the United States and the United Kingdom. Appropriate reclaimed water reuse technology can be used in accordance with national conditions and strength, which also draws attention of the Chinese government at all levels and relevant departments, and undertakes theoretical research and testing. All-star hotels in Guilin can choose appropriate reclaimed water reuse system according to their own strength, in order to collect waste water generated from daily operations of the hotel and process it through the hollow fiber ultrafilter so that the standard water can be used for flushing of the hotel's public toilets, watering of the road greening, car washing and fire protection.

\subsubsection{Application for a new pattern of energy con- servation in energy performance contracting}

Energy performance contracting (EPC for short) is a pattern for an energy service company (ESCO for short in foreign countries, EMCo for short in domestic countries) to implement the energy conservation projects for the enterprise through signing an energy service contract with the enterprise ${ }^{[6]}$. Energy performance contracting is applicable to the service enterprises, especially the hotel industry. The most notable feature of the energy conservation mode is that the investment of the energy conservation projects is undertaken by the energy service company rather than the hotel. The hotel uses the energy conservation benefits to pay service fees and equipment modification costs of the energy service company, which can not only effectively reduce the hotel's funding for the projects of energy conversation and emission reduction, but also help speed up the promotion of the hotel's projects of energy conversation and emission reduction. The star hotels in Guilin can actively cooperate with the energy service company according to their own circumstances, so as to achieve energy conversation and consumption reducing, reduce the carbon emissions and operational costs and facilitate the low-carbon transition of the hotel.

\subsection{Development of low-carbon hotel products}

The development of low-carbon products shall focus on low energy consumption, low pollution and low emissions. The development of low-carbon products must follow the following principles: reduction of the consumption of non-renewable resources, raw materials and energy saving, easy recovery and decomposition, low pollution or no pollution, and no harm to human body and mind. The hotel's low-carbon products mainly include: low-carbon guest rooms, low-carbon dining and low-carbon services.

\subsubsection{Low-carbon guest rooms}

(1) Facility layout of low-carbon guest rooms

The guest rooms are designed with good ventilation and lighting, a good sound insulation and the heat insulation effect. The detection of each pollution index shall be in line with the national standards. Green plants that are beneficial to the health can be placed in the guest rooms of the hotel. The bed linen replacement card can be placed on the bedside of the hotel, which reminds the regular guests to place the replacement card on the bed if they need to replace the bed linen, in order to reduce the laundry workload, the water and electricity consumption and the linen consumption due to frequent replacement of the bed linen. PSM can be used to package six small pieces of the guest room, or six small pieces can be cancelled. Unused six small pieces can be recovered for internal use 
in the hotel. The small refrigerator, electric kettle and other appliances in the guest room can be cancelled, but the ice machine, drinking fountain and vending machine can be configured in the floor of the guest rooms so that the person who are in need can buy what they want.

(2) External shading facilities

The star hotels in Guilin are mostly distributed around two rivers and four lakes. The majority of tourists come here to choose the guest rooms that are close to the rivers and lakes, in order to enjoy the beauty of two rivers and four lakes. The four-star and above hotels in Guilin generally use the whole glass curtain wall, so it is prone to generate thermal radiation, and the temperature index of the guest room rises. Many hotels adopt the processing mode of pasting membrane and choose dark curtains and internal shading, but the solar radiation shielded by the internal shading facilities is the indoor solar radiation, so the heat insulation effect is limited. Based on the initial investment, cleaning and maintenance, it is recommended that the star hotels in Guilin without a large whole glass curtain wall should consider using the external shading facilities.

\subsubsection{Low-carbon dining}

\section{(1) Restaurant service}

There is a need of reasonable distribution of the low priced and easily worn articles (such as napkins, matches, toothpicks) used in the restaurant. At the end of the guests' dining, there is a need to timely recycle unused or remaining napkins, toothpicks and other consumables, so as to eliminate waste. The restaurant shall guide green consumption and economy, and the menu shall explicitly offer large, medium and small cases of services, and the staff shall remind the guests of the volume of the dishes when they order, so as to avoid waste. The staff shall also recommend the guests not to use the disposable tableware. The placemats are placed on the dining table, so as to avoid fouling tablecloths as less as possible, and reduce the quantity of washing. The restaurant managers shall control over the switches of air conditioning and lighting of the restaurant according to the situation of dining, so as to reduce waste.

\section{(2) Low-carbon dining}

The introduction of green, ecological and healthy recipes not only can meet the needs for the people to pursue a healthy diet, but also help to reduce the carbon dioxide emissions. Combined with the local cultural characteristics of ethnic minorities, the star hotels in Guilin can actively develop a green and healthy food market, and introduce vegetarian diet or farm food with the characteristics of ethnic minorities. The three-star and above hotels in Guilin need to reasonably guide the guests, and control over the food waste by reducing the size of the dish; strengthen the presentation of raw materials and flavors of the dishes through menus; properly set up incentive policies to encourage the guests to eat up and reduce the usage amount of the tableware, such as "clean dish campaign", and remind the guests not to waste or package the remaining food at the end of dining, and then they can obtain an exquisite little gift of the restaurant; set up reminders and warnings related to the resources conservation in the restaurant, so as to improve the guest's awareness of resources conservation.

(3) Kitchen

The kitchen is the main energy consumption place of the hotel's food and beverage department. The use of the kitchen equipment has the largest and most direct impact on the energy consumption of the dining. The kitchen equipment is designed with a combined type. The small-scale kitchen equipment is used in case of dining by few guests, without a need to open a large-scale power exhaust blower and cooking equipment. The new energy resources, such as the solar power and commercial electromagnetic stove can be used to reduce the consumption of coal and electricity. The refrigerators, freezers and hot cupboards are equipped with the complete airflow excluders, which can reduce unnecessary energy consumption by the natural way. There is a need to strictly control over the pass rate of the dishes and reduce the phenomenon of returning dishes, so as to eliminate the waste of raw materials. The staff in the dishwashing room shall try to use cold water rather than hot water in the process of washing tableware, and pay attention to saving water resources and liquid detergent and disinfectant in the process of washing and disinfection.

\subsubsection{Low-carbon services}

To develop product standards and provide services, the hotel should actively carry out the concept of environmental protection and low-carbon services, and provide low-carbon products and services in order to reduce the services with high energy consumption, and promote the hotel to achieve low-carbon and energy-saving goals. The hotel can reduce waste through the payment system of "six small pieces" (namely, disposable toothbrush, toothpaste, soap, body wash, slipper and comb) in hotel, and the service staff in the lobby can ask the guests whether they need six small pieces and inform the guests that the six small pieces is not free to provide, and the cost can be replaced as a gift or directly deducted from the room rate when the guests check in. The bathroom goods in the guest rooms are changed from the original portable travel kit to the canned goods for sustainable use by the guests, so as to reduce the waste of bathroom goods. The hotel does not offer or rarely offer disposable consumables, but reminds guests of moderate consumption. The low-carbon services not only embody in the consumption of products, but also embody the products offered by the hotel and after the consumption of products. At the end of the dining, the service staff can actively provide the packaging services if there are leftovers and also provide services of keeping the 
remaining drinks for the guests, which can not only save resources, but also attract the further consumption by the guests.

\subsection{Leading the low-carbon consumption}

The star hotels should bear the responsibility of leading "low-carbon consumption" in the society, and guide the guests to convert the consumption concept to the low-carbon consumption of "reduction", "reuse", "recycle" and "replacement". To guide the consumers to take low-carbon consumption, the star hotels in Guilin can print and place the pamphlets about the common sense of low-carbon consumption in the guest rooms, or shoot the publicity video of the low carbon and environmental protection of the hotel, and play this video in the public areas of the hotel, and publicize the low-carbon concept and low-carbon measures to the society and guests. The hotel can also open the hotel's official microblog on the Internet, release the hotels' low-carbon information on the microblog, launch the microblogging forward and prize quiz activities, and extract lucky guests to free experience the low-carbon guest rooms and services of the hotel, so as to attract consumers. To encourage the guests to take low-carbon consumption, the hotel will provide different loyalty points for the guests if the guests do not use the disposable daily necessities provided by the hotel, or the bed linen in the guest room is replaced for each guest or replaced after three days, or the guests bring their own six small pieces and have other low-carbon behaviors, so the guests can enjoy discount of the room rate, or become VIP members after reaching a certain loyalty point, and the hotel can provide guests with clothes ironing and other free services, present the entrance tickets of the scenic spot to the guests, lead the guests to take low-carbon consumption and improve the guest's enthusiasm to participate in the construction of low-carbon hotel.

For the hotel, the energy conversation and emission reduction can not only highlight the social responsibility of the hotel, thus creating a good social image for the hotel, but also reduce its operating costs and greatly enhance the hotel's profitability. Therefore, as an important "showcase" of the tourism industry, to positively develop "energy-saving and emission-reducing" and low-carbon hotel is a new model of the sustainable development of the star hotel indus- try in the future. As an old-brand tourist city, Guilin is also at the stage of seeking for a new breakthrough when the tourism market faces with fierce competition in the emerging tourism destination. As one of the important pillars of the tourism industry, the star hotels are at the stage of the low-carbon transition, and carrying out energy conservation and emission reduction, which become leaders of the energy consumption reduction, energy conversation and environmental protection, and play a significant role in promoting and facilitating the low-carbon development of the tourism industry in Guilin.

\section{ACKNOWLEDGEMENT}

This paper is financially supported by Philosophy and Social Science Planning Research Project of Guangxi Province, China-" Research on the Coupling Relationship between the Economic Development of Tourism and the Ecological Environment"(GN: 13FGL017) and Educational Commission of Guangxi Province, China-"Research on the Coordinating Developing Locus and Mode of Tourism and Ecological Environment of Guangxi Province based on the Ecological Civilization" (GN: YB2014359).

\section{REFERENCES}

[1] Li Ping. 2011. Development strategy of hotel industry under the low-carbon economy in China. Hotel Modern ization, (3): 64-65.

[2] Sun Jianchao. 2003. Application of environmental issues and ISO4000 of the hotel industry in hotel. China Environmental Management, (6): 33-34.

[3] Gossling S. 2002. Global environmental consequences of tourism. Global Environmental Change, 12(4): 283-302.

[4] Shi Peihua \& Wu Pu. 2011. Preliminary estimates of energy consumption and $\mathrm{CO} 2$ emissions in China's tourism industry. Journal of Geographical Sciences, (2): 235-243.

[5] Wang Lina \& Wu Yi. 2012. Low-carbon tourism development research based on the status quo of energy conservation and emission reduction. Journal of Chifeng University (Natural Sciences), (5): 92-93.

[6] Tian Jizan, Li Ming \& Guan Rui. 2007. "Energy performance contracting" mode and energy-saving and cost-reducing strategy. Economic Perspectives, (11): 70-71. 